\title{
z Research SGutare \\ The Effect of Periodic Ketogenic Diet on Newly Diagnosed Overweight or Obese Patients with Type 2 Diabetes
}

Sumei Li ( $\sim$ ptsyy.lsm@163.com )

the first hospital of PutianखFu Jian囚China https://orcid.org/0000-0002-6963-5309

Guoxin Lin

the first I Hospital of Putian, Fujian

Jinxing Chen

the first I Hospital of Putian, Fujian

Zhenxin Chen

the first I Hospital of Putian, Fujian

Feipeng Xu

the first I Hospital of Putian, Fujian

Feng Zhu

the first I Hospital of Putian, Fujian

Jintian Zhang

Putian University, Fujian

Shouping Yuan

the first I Hospital of Putian, Fujian

\section{Research article}

Keywords: Ketogenic diet, Obesit, Being overweight, Type 2 diabetes, Newly diagnosis

Posted Date: September 14th, 2020

DOI: https://doi.org/10.21203/rs.3.rs-34974/v2

License: (c) (i) This work is licensed under a Creative Commons Attribution 4.0 International License.

Read Full License

Version of Record: A version of this preprint was published at BMC Endocrine Disorders on February 3rd, 2022. See the published version at https://doi.org/10.1186/s12902-022-00947-2. 


\section{Abstract}

\section{Background}

To observe the effect of periodic ketogenic diet intervention on newly diagnosed overweight or obese patients with type 2 diabetes.

\section{Methods}

60 overweight or obese T2DM patients were randomly divided into ketogenic diet group and diabetes diet control group, 30 patients in each group. The changes and significance of blood glucose, blood lipid, body weight, insulin, uric acid and other indicators before and after the intervention were observed.

Results

The Weight, BMI, Waist, TG, TC, LDL, HDL, FBG, FINS, HbA1c of the two groups decreased significantly compared with the previous period $(P<0.05)$. However, UA showed an increasing trend in the ketogenic diet group and no significant change in UA in the diabetic diet control group $(P>0.05)$. Long-term adherence to the ketogenic diet was not as strong as that of the diabetic diet.

Conclusion

The phased-ketogenic diet can control not only weight but also blood glucose and blood lipid in patients with overweight or obese T2DM. But long-term persistence is difficult.

\section{Background}

By 2013 , the prevalence rate of diabetes in Chinese aged 18 and above was as high as $10.4 \%{ }^{[1]}$. At the same time, the number of obese people is also increasing year by year.Data show that the higher the body mass index is in obese people, the higher the prevalence rate of type 2 diabetes is ${ }^{[2]}$. Data show that very low carbohydrate ${ }^{[3-9]}$, adequate sleep, and appropriate exercise can improve glycemic control and weight loss in type 2 diabetes. The Ketogenic diet (KD) is a diet pattern of high fat content, low carbohydrates, and appropriate protein. It replaces carbohydrates with fat as the main energy source, and was first used to treat intractable epilepsy in children ${ }^{[10-11]}$. In recent years, scholars have found that this diet pattern has benefits in weight loss and blood glucose control. The purpose of this study was to observe the efficacy of periodic ketogenic diet in patients with newly diagnosed overweight or obese type 2 diabetes.

\section{Methods}

\subsection{General Information}


From June 1, 2018 to June 1, 2020, 60 patients with type 2 diabetes who were newly diagnosed as overweight or obese were admitted to the endocrinology department of our hospital. There were 32 males and 28 females. There was no gender preference. All patients gave informed consent. They were randomly divided into two groups, ketogenic diet group and diabetes diet control group, with 30 patients in each group. The changes and significance of each index before and after the intervention were observed. Inclusion criteria: Age 18-50 years old, $\mathrm{BMI} \geq 25 \mathrm{~kg} / \mathrm{m} 2$, newly diagnosed type 2 diabetes, no history of hypoglycemic drugs, the course of diabetes was less than half a year, hemoglobin a $1 \mathrm{c}<10 \%$. Exclusion criteria: merge heart lung, kidney and other important organs history of severe disease, type 2 diabetes than other types of diabetes, accompanied by diabetes history, severe complication of acute or chronic infections, such as pregnancy, trauma, surgical stress status, pregnancy and lactation women, can lead to glucose metabolic disorder, use of drugs such as corticosteroids, etc.

\subsection{Methods}

The 60 patients were randomly divided into two groups, namely the ketogenic diet group and the diabetes diet control group. Ketobiological diet group: ingredients mainly come from olive oil, butter, Fried eggs, double-cooked meat, Fried salmon, anchovies, sardines, broccoli, avocado, etc. Control daily carbohydrate $30-50 \mathrm{~g}$, protein $60 \mathrm{~g}$, fat $130 \mathrm{~g}$, total calorie $(1500 \pm 50) \mathrm{kCal}$. In the diabetes diet control group, there was no restriction on food materials. Daily carbohydrate $250-280 \mathrm{~g}$, protein $60 \mathrm{~g}$, fat $20 \mathrm{~g}$ and total calories $(1500$ $\pm 50) \mathrm{KCal}$ were controlled. During the diet control period, the two groups should drink more than $2000 \mathrm{ml}$ of water per day. All participants were evaluated at baseline and 12 weeks after intervention. FBG (fasting glucose) and FINS (fasting insulin) were measured. Height, weight and waist circumference of the patients were measured and body mass index (BMI) was calculated. Meanwhile, $\mathrm{HbA1c}$ (glycosylated hemoglobin), UA (serum uric acid), TC (cholesterol), LDL-C (low-density lipoprotein cholesterol), HDL-C (high-density lipoprotein cholesterol) and TG (triglyceride) were detected. All subjects underwent a 12week diet intervention. The incidence of hypoglycemia was recorded during the period. Symptoms of hypoglycemia: hunger, cold sweat, palpitation, hand shaking, fatigue, etc. Hypoglycemia events: blood glucose $<3.9 \mathrm{mmol} / \mathrm{L}$.

\subsection{Statistical Analysis}

SPSS 22.0 software was used for statistics, and the results were presented. T-test or rank sum test was used for data comparison between and within groups, and chi-square test was used for rate comparison. $\mathrm{P}<0.05$ was considered statistically significant.

\section{Results}

Table 1 Comparison of general data between the two groups before intervention $(\bar{\chi} \pm S D)$ 


\begin{tabular}{|c|c|c|c|}
\hline project & The ketogenic diet group & The diabetic diet group & $\mathbf{P}$ \\
\hline Age (yr) & $36.50 \pm 13.67$ & $37.10 \pm 14.02$ & 0.657 \\
\hline Course(month) & $3.51 \pm 1.40$ & $3.42 \pm 1.38$ & 0.537 \\
\hline Waist(cm) & $108.53 \pm 12.13$ & $107.33 \pm 12.07$ & 0.712 \\
\hline Weight (kg) & $78.32 \pm 15.27$ & $77.95 \pm 14.76$ & 0.854 \\
\hline BMI (kg/m2) & $29.04 \pm 5.81$ & $29.75 \pm 6.07$ & 0.934 \\
\hline UA(umol/L) & $378.23 \pm 24.35$ & $381.42 \pm 26.64$ & 0.669 \\
\hline $\mathrm{HbA1C} \otimes \% \rrbracket$ & $8.74 \pm 1.63$ & $8.69 \pm 1.59$ & 0.673 \\
\hline $\mathrm{FBG}(\mathrm{mmol} / \mathrm{L})$ & $9.01 \pm 2.77$ & $8.98 \pm 2.48$ & 0.940 \\
\hline FINS (pmol/L) & $48.61 \pm 17.83$ & $45.9 \pm 14.38$ & 0.687 \\
\hline LDL (mmol/L) & $2.75 \pm 0.65$ & $2.77 \pm 0.69$ & 0.864 \\
\hline $\mathrm{HDL}(\mathrm{mmol} / \mathrm{L})$ & $1.08 \pm 0.11$ & $1.09 \pm 0.19$ & 0.469 \\
\hline TG (mmol/L) & $1.76 \pm 0.59$ & $1.81 \pm 0.78$ & 0.717 \\
\hline $\mathrm{TC}(\mathrm{mmol} / \mathrm{L})$ & $4.54 \pm 0.69$ & $4.56 \pm 0.67$ & 0.830 \\
\hline
\end{tabular}

2.1 comparison of general data before intervention there were no statistically significant differences in gender, age and course of disease between the two groups before intervention, while there were no statistically significant differences in Weight, BMI, Waist, TG, TC, LDL, HDL, FBG, FINS, HbA1c, UA and other indicators before intervention $(P>0.05)$, as shown in table 1 .

2.2 Changes of various indicators in the two groups before and after the intervention (Table 2) after 12 weeks, 6 patients in the ketogenation group dropped out of the trial due to non-adherence, and 24 patients completed the project. One person quit the group and 29 people finished the project. The Weight, BMI, Waist, TG, TC, LDL, HDL, FBG, FINS, HbA1c of the two groups were all decreased compared with the previous period $(P<0.05)$, and the body mass, blood lipid, blood glucose and other indexes of the ketobiotic diet group were significantly lower than those of the conventional diabetes diet control group $(P<0.05)$. In the ketogenic diet group, UA showed an increasing trend, while in the routine diabetes diet control group, the changes in UA were not statistically significant $(P>0.05)$.

Table 2 Changes of indicators before and after intervention of different dietary patterns in the two groups $(\bar{\chi} \pm S D)$ 


\begin{tabular}{|c|c|c|c|c|c|c|}
\hline \multirow[t]{2}{*}{ project } & \multicolumn{2}{|c|}{ The ketogenic diet group $\ n=24 \rrbracket$} & \multirow[t]{2}{*}{$\mathrm{P}$} & \multicolumn{2}{|c|}{ The diabetic diet group $\ n=29 \rrbracket$} & \multirow[t]{2}{*}{$P$} \\
\hline & $\begin{array}{l}\text { Before the } \\
\text { intervention }\end{array}$ & $\begin{array}{l}\text { After } 12 \text { weeks } \\
\text { of intervention }\end{array}$ & & $\begin{array}{l}\text { Before the } \\
\text { intervention }\end{array}$ & $\begin{array}{l}\text { After } 12 \text { weeks } \\
\text { of intervention }\end{array}$ & \\
\hline Waist(cm) & $108.53 \pm 12.13$ & $99.24 \pm 14.58$ & 0.000 & $107.33 \pm 12.07$ & $106.56 \pm 9.78$ & 0.000 \\
\hline $\begin{array}{l}\text { Weight } \\
(\mathrm{kg})\end{array}$ & $78.32 \pm 15.27$ & $70.26 \pm 14.79$ & 0.000 & $77.95 \pm 14.76$ & $77.34 \pm 13.28$ & 0.000 \\
\hline $\begin{array}{l}\mathrm{BMI} \\
(\mathrm{kg} / \mathrm{m} 2)\end{array}$ & $29.04 \pm 5.81$ & $26.21 \pm 5.74$ & 0.000 & $29.75 \pm 6.07$ & $29.42 \pm 5.97$ & 0.000 \\
\hline 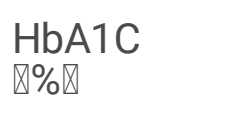 & $8.74 \pm 1.63$ & $7.82 \pm 1.43$ & 0.000 & $8.69 \pm 1.59$ & $8.42 \pm 1.51$ & 0.000 \\
\hline $\begin{array}{l}\text { FBG } \\
(\mathrm{mmol} / \mathrm{L})\end{array}$ & $9.01 \pm 2.77$ & $7.62 \pm 1.69$ & 0.000 & $8.98 \pm 2.48$ & $8.42 \pm 2.17$ & 0.000 \\
\hline $\begin{array}{l}\text { FINS } \\
\text { (pmol/L) }\end{array}$ & $88.61 \pm 17.83$ & $40.38 \pm 9.54$ & 0.000 & $87.91 \pm 14.38$ & $84.21 \pm 10.79$ & 0.000 \\
\hline $\begin{array}{l}\mathrm{LDL} \\
(\mathrm{mmol} / \mathrm{L})\end{array}$ & $2.75 \pm 0.65$ & $2.34 \pm 0.45$ & 0.018 & $2.77 \pm 0.69$ & $2.59 \pm 0.58$ & 0.139 \\
\hline $\begin{array}{l}\mathrm{HDL} \\
(\mathrm{mmol} / \mathrm{L})\end{array}$ & $1.08 \pm 0.11$ & $1.21 \pm 0.23$ & 0.000 & $1.09 \pm 0.19$ & $1.12 \pm 0.20$ & 0.000 \\
\hline $\begin{array}{l}\text { TG } \\
(\mathrm{mmol} / \mathrm{L})\end{array}$ & $1.76 \pm 0.59$ & $1.44 \pm 0.26$ & 0.000 & $1.81 \pm 0.78$ & $1.66 \pm 0.46$ & 0.000 \\
\hline $\begin{array}{l}\text { TC } \\
(\mathrm{mmol} / \mathrm{L})\end{array}$ & $4.54 \pm 0.69$ & $4.02 \pm 0.43$ & 0.000 & $4.56 \pm 0.67$ & $4.23 \pm 0.47$ & 0.000 \\
\hline $\begin{array}{l}\text { UA } \\
\text { (umol/L) }\end{array}$ & $378.23 \pm 24.35$ & $467.43 \pm 35.67$ & 0.000 & $381.42 \pm 26.64$ & $378 \llbracket 54 \pm 25.79$ & 0.237 \\
\hline
\end{tabular}

In week 1-4 of intervention, 10 times of hypoglycemia occurred in the ketogenic diet group, that is, 2 times of peripheral blood glucose $<3.9 \mathrm{mmol} / \mathrm{L}$. In the diabetes diet control group, hypoglycemia was observed 2 times, i.e., 0 times when peripheral blood glucose $<3.9 \mathrm{mmol} / \mathrm{L}$ was measured. No further hypoglycemia events occurred during 5-12 weeks of intervention. At the end of the intervention 9 patients on the ketogenic diet had normal blood glucose levels. Two patients in the diabetic diet control group had normal blood glucose.

2.4 Patients' willingness to adhere to the diet was followed up after the end of the follow-up project. The ketogenic diet group was found to have significantly lower rates of long-term adherence than the regular diabetes group. The reason is that most patients find carbohydrate-deficient foods unpleasant. The results are shown in Table 3.

Table 3. Differences in intentions after completion of projects between the two groups 


\begin{tabular}{|c|c|c|c|}
\hline & $\begin{array}{l}\text { The ketogenic } \\
\text { diet group }\end{array}$ & $\begin{array}{l}\text { The diabetic diet } \\
\text { group }\end{array}$ & $\mathrm{p}$ \\
\hline $\begin{array}{l}\text { Number of people who cannot stick to it } \\
\text { (percentage) }\end{array}$ & $6 \rrbracket 20 \% \rrbracket$ & 1区3.3\%】 & $<0.05$ \\
\hline $\begin{array}{l}\text { Number of People willing to stick with it in the } \\
\text { short term (proportion) }\end{array}$ & 19ه63.3\%》 & $5 \rrbracket 16.7 \% \rrbracket$ & $<0.05$ \\
\hline $\begin{array}{l}\text { Number of people willing to stick with it for the } \\
\text { long term (proportion) }\end{array}$ & 5 \16.7\%】 & 24 \80\%区 & $<0.05$ \\
\hline
\end{tabular}

\section{Discussion}

The incidence of type 2 diabetes is increasing year by year. The main environmental factors of type 2 diabetes include high calorie diet, obesity and insufficient physical activity. In the world, the obesity epidemic, on the one hand, has caused an increase in the morbidity and mortality of cardiovascular and cerebrovascular diseases, diabetes, tumors and other diseases ${ }^{[12]}$. On the other hand, it has objectively increased huge medical and health costs, effectively controlling obesity, which can reduce and save a lot of medical expenditures caused by it ${ }^{[12-13]}$. Studies ${ }^{[14]}$ showed that increasing daily exercise and dietary intervention can reduce the occurrence of type 2 diabetes, effectively reduce weight, and reduce the risk of all-cause death and cardiovascular death and other end events. In this study, for overweight or obese patients with type 2 diabetes, ketogenic diet was administered for 12 weeks before the application of hypoglycemic drugs to observe the changes in blood glucose, lipid, body weight, uric acid, insulin resistance and other related indicators.

The ketogenic diet model is often questioned by scholars because of its high fat ratio and extremely low carbohydrate content. Until a PURE study published in The Lancet in $2017^{[15]}$ proposed that excessive carbohydrate intake was positively correlated with the increase in the risk of total mortality, and scholars re-evaluated the value of ketogenic diet. Ketogenic diet is a dietary pattern deduced by theoretical research. As a therapeutic dietary pattern, it has accumulated a lot of scientific knowledge and has certain theoretical advantages and practicability ${ }^{[16]}$.

Ketogenic diet because of its low carbohydrate content, to simulate the body state of hunger, the formation of hunger ketosis, change into the body's energy supply mode is given priority to with ketone bodies replace is given priority to with glucose, in the form of energy supply mode, the energy supply modes of promoting fat catabolism reduced fat synthesis, increased energy consumption increased sugar dysplasia, that does not dissolve in water turn triglycerides in water soluble ketone body (acetoacetate, beta - hydroxybutyric acid soluble in water, acetone insoluble in water), so can the excretion of urine ketone body ruled out further in vitro ${ }^{[17]}$ take energy at the same time. In addition, the increase of ketone body in the body can suppress appetite ${ }^{[18]}$, so the principle of reducing fat in ketogenic diet is cut in multiple ways ${ }^{[19]}$. This also explains why the ketogenic diet, although consuming 
foods with a high percentage of fat, can reduce lipid metabolic indicators such as triglycerides, total cholesterol and low-density lipoprotein. This is consistent with the results of this study.

The ketogenic diet emphasizes that the intake of carbohydrates is extremely low, and the reduction of carbohydrate intake can affect the basic metabolism of sugar by regulating the breakdown rate of liver glycogen, thus reducing blood glucose ${ }^{[20]}$. It reduces absorption of intestinal monosaccharides, lowers blood sugar and reduces fluctuations in blood sugar. A Goday et al. ${ }^{[21]}$ proved that the short-term ketogenic diet was safe, tolerable and effective for patients with type 2 diabetes.

Myette. Cote et al. ${ }^{[22]}$ proved through studies that ketogenic diet can rapidly and significantly improve patients' blood glucose control. Due to the control of blood glucose, the reactive fasting insulin level will decrease, stabilize the blood glucose of patients with type 2 diabetes and reduce the fluctuation of blood glucose. Laura R Saslow et al. ${ }^{[23]}$ also achieved the control of blood glucose and weight by online intervention in the diet structure of overweight t2DM patients. Partsalaki I et al. ${ }^{[24]}$ showed that ketogenic diet could reduce waist circumference and body weight, as well as insulin resistance. Waist circumference is an important indicator of central obesity and a related factor of insulin resistance. In this study, waist circumference decreased, body mass decreased, blood glucose control decreased, insulin resistance decreased, and related lipid metabolism indexes of the study subjects were improved. The reduction of body mass was closely related to the application of ketogenic diet structure, and was also closely related to the negative nitrogen balance caused by calorie restriction. Therefore, in the control group, the diabetes diet control group given relatively low calorie was also improved in all relevant indicators. A relatively low calorific calorie intake should be given to individuals; otherwise, even a ketogenic diet cannot significantly improve the composition of the body ${ }^{[25]}$. The subjects of this study were overweight or obese patients with newly diagnosed type 2 diabetes, who often had significant insulin resistance and a certain degree of islet function decline. Ketogenic diet could significantly reduce insulin resistance, as well as weight and fat loss. So you can control your blood sugar more smoothly. Innovation point of this study selected the crowd is early diagnosis, not application of drugs to keep blood sugar under control, overweight, or obese patients, through the adjustment of the ketogenic diet, some patients may reach diabetes, only lifestyle changes can reach the control of blood sugar, but only 12 weeks of observation time, this study also can't clear the development of blood glucose after ketogenic diet has stopped. At the same time, attention should be paid to the occurrence of hypoglycemia during the ketogenic diet, especially during the first 4 weeks. Although all patients tolerated at the later stage, attention should still be paid. In addition, it cannot be ignored that ketogenic diet is accompanied by the inevitable increase of serum uric acid, which increases the risk of gout attack. Therefore, during the intervention, it is necessary to drink more water to promote uric acid excretion, and if necessary, alkalize urine with sodium bicarbonate to facilitate uric acid excretion and reduce the risk of hyperuricemia. Undeniably, although ketogenic diet has a great impact on weight loss and type 2 diabetes, the very low carbohydrate diet is not what most people are willing to adhere to in their daily life for a long time, which can only be used as a short-term treatment model diet. 


\section{Conclusion}

The phased-ketogenic diet can control not only weight but also blood glucose and blood lipid in patients with overweight or obese T2DM. But long-term persistence is difficult. It can be a therapeutic model of diet. Some newly diagnosed overweight or obese people with type 2 diabetes may benefit from losing weight while getting better results with diabetes remission. For type 2 diabetes, there may be a time when you're completely off medication.

\section{Abbreviations}

KD Ketogenic diet

FBG Fasting glucose

FINS Fasting insulin

BMI Body mass index

HbA1c Glycosylated hemoglobin

UA Serum uric acid

TC Cholesterol

LDL-C Low-density lipoprotein cholesterol

HDL-C High-density lipoprotein cholesterol

TG Triglyceride

\section{Declarations}

\section{- Ethics approval and consent to participate}

Ethical clearance and approval were obtained from Ethics Committee of the first I Hospital of Putian, Fujian , China. All study participants were informed about the purpose of the study and additional information was given as they need. Written informed consent was obtained from all participants. We had complied with the Declaration of Helsinki Ethical Principles for medical research involving human subjects [26].

\section{- $\quad$ Consent to publish}

This manuscript does not report personal data such as individual details, images or videos; therefore, consent for publication is not applicable. 


\section{- $\quad$ Availability of data and materials}

The datasets used in the analyses described in this study are available from the corresponding author on reasonable request.

\section{- $\quad$ Competing interests}

The authors declare that they have no competing interests.

\section{- $\quad$ Funding}

This work was supported by Putian Science and Technology Bureau, Fujian province, China. The funding agency was not involved in the design of the study, collection, analysis, and interpretation of data, or preparation of the manuscript.

\section{- $\quad$ Authors' Contributions}

SM L conceived, designed and developed the project. SMLstudied the data and wrote the manuscript, GX $L$ and $J X C$ reviewed/edited the manuscript and participated in the discussion, ZXC commented/edited the manuscript and participated in the discussion ,FP X and FZ collected data and made statistical analysis. JTZ and SPY followed up the patients and contributed to the discussion. All authors read and approved the final manuscript.

\section{- $\quad$ Acknowledgements}

Thank you very much to all the investigators and patients involved in this work.

\section{References}

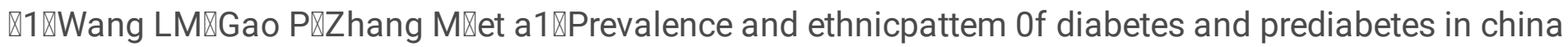

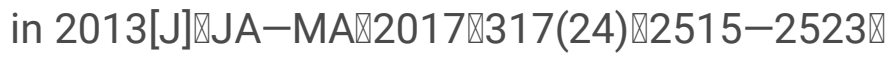

\2囚GBD 2015 Obesity Collaborators $₫ A F S H I N$ AखFOROUZANFAR MH囚et al. Health effects of overweight

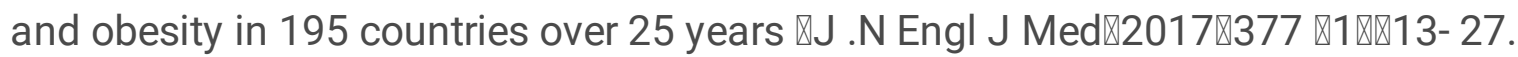

$₫ 3 \bigotimes$ Ruskin DN, Masino SA. The nervous system and metabolic dysregulation: emerging evidence converges on ketogenic diet therapy. Front Neurosci. 2012;6:33. doi: 10.3389/fnins.2012.00033. doi: 10.3389/fnins.2012.00033.

\4囚 Dashti HM, Mathew TC, Khadada M, \et a1. Beneficial effects of ketogenic diet in obese diabetic subjects. Mol Cell Biochem. 2007 Aug;302(1-2):249-256. doi: 10.1007/s11010-007-9448-z.

\5囚Feinman RD, Pogozelski WK, Astrup A, \et a1. Dietary carbohydrate restriction as the first approach in diabetes management: critical review and evidence base. Nutrition. 2015 Jan;31(1):1-13. doi: 10.1016/j.nut.2014.06.011. 
Q6ه Bistrian BR, Blackburn GL, Flatt JP, et a1. Nitrogen metabolism and insulin requirements in obese diabetic adults on a protein-sparing modified fast. Diabetes. 1976 Jun;25(6):494-504.

Q7凶Volek JS, Phinney SD, Forsythe CE,et a1. Carbohydrate restriction has a more favorable impact on the metabolic syndrome than a low fat diet. Lipids. 2009 Apr;44(4):297-309. doi: 10.1007/s11745-008-32742 .

\8\Kirk JK, Graves DE, Craven TE, et a1. Restricted-carbohydrate diets in patients with type 2 diabetes: a meta-analysis. J Am Diet Assoc. 2008 Jan;108(1):91-100. doi: 10.1016/j.jada.2007.10.003.

\9\ Accurso A, Bernstein RK, Dahlqvist A, D囚et a1. Dietary carbohydrate restriction in type 2 diabetes mellitus and metabolic syndrome: time for a critical appraisal. Nutr Metab (Lond) 2008;5:9. doi: 10.1186/1743-7075-5-9.

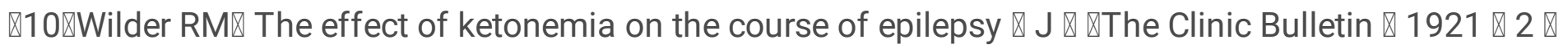
$307 \rrbracket 308$.

$\nabla 11 \rrbracket$ Caraballo $\mathrm{R} \otimes$ Noli $\mathrm{D} \otimes$ Cachia $\mathrm{P} \otimes$ Epilepsy of infancy with migrating focal seizures $\otimes$ three patients

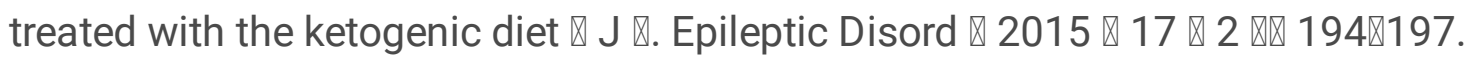

ه12هCole CB, Nikpay M, Stewart AF, et al. Increased genetic risk for obesity in premature coronary artery disease. Eur J Hum Genet. 2016;24(4):587-591.

ه13凶Williams EP, Mesidor M, Winters K, et al. Overweight and obesity: prevalence, consequences, and causes of a growing public health problem. Curr Obes Rep. 2015;4(3):363-370.

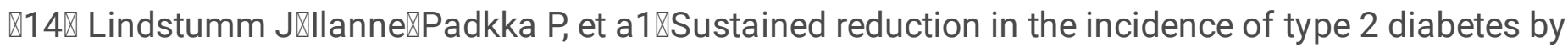
lifestyle intervention: follow-up of the Finnish Diabetes Prevention Study [J]षThe Lancet $2006 \rrbracket$ 368(9548) ه1673-1679凶

$\triangle 15 \otimes$ Mahshid Dehghan $\otimes$ Andrew Mente $\otimes$ Xiaohe Zhang $\otimes$ et al. Associations of fats and carbohydrate intake with cardiovascular disease and mortality in 18 countries from five continents $\triangle$ PURE $\mathbb{\text { Q }}$ a prospective cohort study $\otimes J \otimes$. The Lancet $\otimes 2017 \otimes 390 \otimes 8 \otimes \square 2050-2062$.

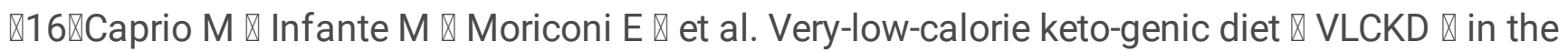
management of metabolic diseases \systematic review and consensus statement from the Italian

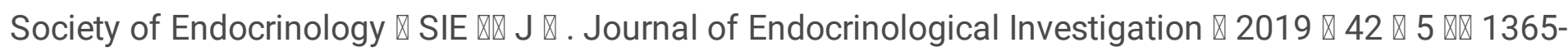
1386.

Q17ه Urbain P, Bertz $\mathrm{H}$. Monitoring for compliance with a ketogenic diet: what is the best time of day to test for urinary ketosis? Nutr Metab (Lond). 2016;13:77.

Q18 .Nymo S, Coutinho SR, Jorgensen J, et al. Timeline of changes in appetite during weight loss with a ketogenic diet. Int J Obes (Lond). 2017. 
\$19ه .Paoli A, Rubini A, Volek JS, et al. Beyond weight loss: a review of the therapeutic uses of very-lowcarbohydrate (ketogenic) diets. Eur J Clin Nutr. 2013;67(8):789-796.

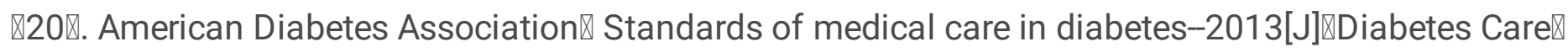
2013®36(Suppl 1)『S11-66囚

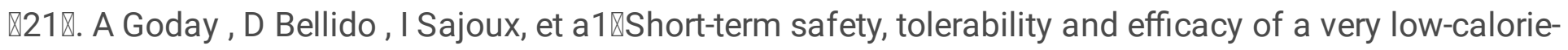
ketogenic diet interventional weight loss program

versus hypocaloric diet in patients with type 2 diabetes mellitus. Nutrition \& Diabetes (2016) 6, e230; doi:10.1038/nutd.2016.36.

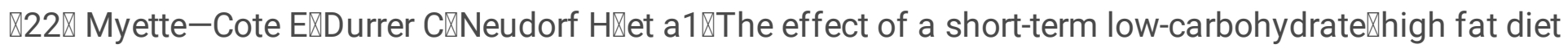
with or without postmeal walks on glycemic con $\square$ and innammalion jn type 2 diabetes $₫ a$ randomized tria1[J]区Am J Physiol Regul Integr Comp Physiol . 2018 Dec 1;315(6):R1210-R1219.

ه23هLaura R Saslow, Ashley E Mason,Sarah Kim, et al. An Online Intervention Comparing a Very LowCarbohydrate Ketogenic Diet and Lifestyle Recommendations Versus a Plate Method Diet in Overweight Individuals With Type 2 Diabetes: A Randomized Controlled Trial. J Med Internet Res. 2017 Feb; 19(2): e36.

$\llbracket 24 \rrbracket$ Insalaki I $₫$ Karvela A $\llbracket$ spiliotis B E $\llbracket$ Metabolic impact of a ketogenic diet compared to a hypocaloric

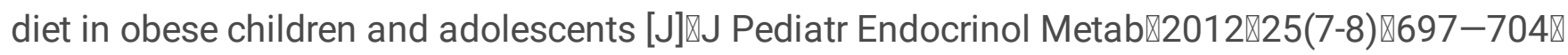

$\triangle 25 \otimes$ Hall $K D \otimes C h e n K Y \otimes G u o ~ J \nabla$ et al. Energy expenditure and body composition changes after an

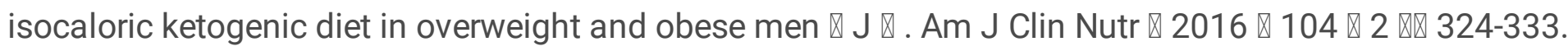

